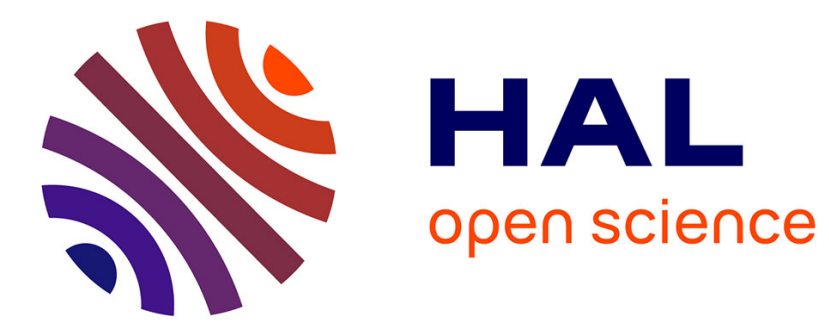

\title{
THE GENERALIZED PSEUDOATOM FORMALISM IN LATTICE DYNAMICS
}

\author{
M. Ball
}

\section{To cite this version:}

M. Ball. THE GENERALIZED PSEUDOATOM FORMALISM IN LATTICE DYNAMICS. Journal de Physique Colloques, 1981, 42 (C6), pp.C6-519-C6-521. 10.1051/jphyscol:19816151 . jpa-00221217

\section{HAL Id: jpa-00221217 https://hal.science/jpa-00221217}

Submitted on 1 Jan 1981

HAL is a multi-disciplinary open access archive for the deposit and dissemination of scientific research documents, whether they are published or not. The documents may come from teaching and research institutions in France or abroad, or from public or private research centers.
L'archive ouverte pluridisciplinaire HAL, est destinée au dépôt et à la diffusion de documents scientifiques de niveau recherche, publiés ou non, émanant des établissements d'enseignement et de recherche français ou étrangers, des laboratoires publics ou privés. 
JOURNAL DE PHYSIQUE

Colzoque C6, supplément au no 12, Tome 42, décembre 1981

page $\quad 66-519$

\title{
THE GENERALIZED PSEUDOATOM FORMALISM IN LATTICE DYNAMICS
}

\author{
M.A. Ba11 \\ D.A.M.T.P., University of Liverpool, Liverpoot L69 3BX, U.K.
}

\section{Abstract.}

The change $I$ in potential due to a phonon is expressed in terms of the susceptibility and the effective charge vector. It is analytic in metals or where $z$ eff is zero, and hence can be uniquely split into parts which rigid7y fỗllow the ions and parts which deform as the ions move. This 'generalised pseudoatom' is neutral. The dynamical matrix is expressed in terms of I both in the reciprocal lattice representation and other representãtions.

We show first that the charge density of a finite system is a sum of uniquelydefined pseudoatoms, each consisting of a part moving rigidly with an ion and a part which deforms $/ 1 /$. Suppose the ion at $R_{\sim j}^{0}$ moves to $R_{\sim j}^{0}+\delta R_{j}$. The change in charge density to first-order is $f_{j}(r) . \delta R_{j}$. Now $f_{j}(r)$ can be written

$$
f_{j}(r)=-\nabla \rho_{j}\left(r-R_{j}^{0}\right)+\underset{\sim}{\nabla} \times \underset{\sim}{\sim} \tilde{B}_{j}\left(r^{\sim j}-\underset{\sim}{R}\right)
$$

Thus to first order in $\delta R_{j}$, the total charge density of the system is

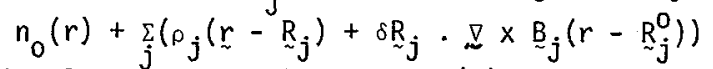

Translational invariance /T/ makes $n_{0}(r)$ zero. The term $\rho_{j}\left(r-r_{\sim}\right)$ is the part which moves rigidly with the ion and the other term is the deformation.

In crystals the ions move collectively as phonons. For (2) to be valid, the charge density must be analytic in $q$, the wave-vector of the phonon. Let the equilibrium position vector of the $\kappa$ ion in the unit cell at $\underset{\sim}{\ell}$ be $\underset{\sim}{R^{0}}(\underset{\sim}{\ell}, k) \equiv \underset{\sim}{\ell}+\mathbb{R}^{0}$ $(k)$. This is displaced $\delta R(k) \exp \left[i q \cdot R^{0}(\ell, k)\right]$ by the phonon. The change in the electronic charge density is written



where $g$ are reciprocal lattice vectors and $\tau$ is the cell volume. The change in the total charge density is written $\underset{\sim}{f}(g+g, k)$. We write the potential of the nucleus and the core eiectrons as $W(\underset{\sim}{r}-\underset{\sim}{R}(\underset{\sim}{\ell}, k) ; k)$. Then



The electron-phonon operator can be expressed in terias of $f$ and $H$.

$$
I(\underset{\sim}{q}+\underset{\sim}{g}, k)=i(\underset{\sim}{q}+\underset{\sim}{g}) W(\underset{\sim}{q}+\underset{\sim}{g}, k)+v(\underset{\sim}{q}+\underset{\sim}{g}) \underset{\sim}{f}(\underset{\sim}{q}+\underset{\sim}{g}, \tilde{k})
$$

where $v$ is the Couiomb interaction. Then

$$
I(\underline{q}+\underset{\sim}{g}, k)=i_{g^{\prime}} \Sigma \varepsilon^{-1}\left(\underline{q}+\underset{\sim}{g}, \underset{\sim}{q}+\underline{\sim}^{\prime}\right)\left(\underline{q}+\underline{q}^{\prime}\right) W(\underline{q}+\underset{\sim}{g}, k) \exp \left[i\left(\underset{\sim}{g}-g^{\prime}\right) \cdot R(k)\right]
$$


where $\varepsilon$ is the dielectric function matrix. Inverting /2/

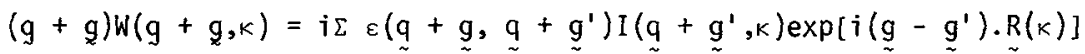

$I$ is the change in potential felt by a classical point charge. I' is the change felt by a valence electron: it includes exchange and correlation.

To investigate the analyticity of $\underset{\sim}{\mathrm{I}}$, we write $\mathrm{I}(\mathrm{q}+\underset{\sim}{\mathrm{g}}, \mathrm{k})$ in terms of the 'susceptibility' $\underset{x}{\alpha}$ and the effective charge vector $\underset{\sim}{\tilde{z}}(\underset{\sim}{q}, k) / 3 /$ :

$$
\hat{x}=x+x\left(\frac{\Lambda}{2}-v\right) \dot{\chi}
$$

$$
\begin{aligned}
& \underset{\sim}{Z}(\underset{\sim}{q}+\underset{\sim}{g}, k)=-i\left((\underline{q}+\underset{\sim}{g}) W(\underline{q}+\underset{\sim}{g}, k) / v(\underset{\sim}{q}+\underset{\sim}{g})+\Sigma_{g^{\prime}} \neq \hat{x}(q)+g, q+g^{\prime}\right)
\end{aligned}
$$

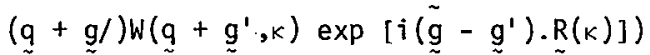

In insulators and metals $\left.\lim _{q \rightarrow 0} \underset{\sim}{z} \underset{\sim}{q}, k\right)=i \underset{\sim}{i}{\underset{\sim}{\text { eff }}(\kappa) \cdot q}_{\sim}^{q}$

where $z^{\text {eff }}(\kappa)$ is the effective charge tensor. Hence



and

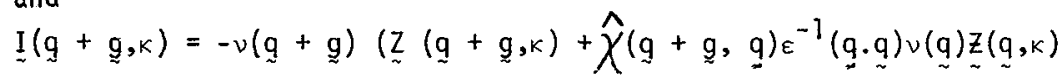

There can only be non-analytic behaviour in the limit $q \rightarrow 0$. In insulators the second term in (12) is non-analytic if $z^{\text {eff }}(k)$ is non-zero so $\underset{\sim}{I}(q+g, k)$ is analytic if and only if ${\underset{\approx}{z}}^{\text {eff }}(k)$ is zero. In a metal $\nu(\underset{\sim}{q}) e^{-1}(\underset{\sim}{g}, q) \rightarrow-1 / \tilde{\alpha}_{\chi}^{\Lambda}(\underset{\sim}{q}, q)$, both $\Lambda(q, q)$ and $\Lambda(q+q, q)$ tend to a finite limit and $I(\tilde{q}+q(\tilde{q}, \tilde{q})$ is always analytic.

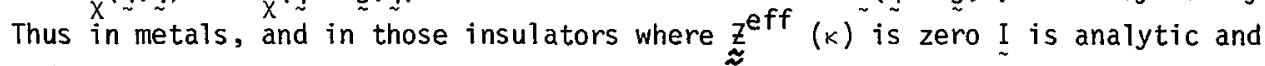
and so are $I_{\sim}^{\prime}$ and f. Each such vector field can be uniquely decomposed into vectors parallel and perpendicular to $q+g$, i.e.

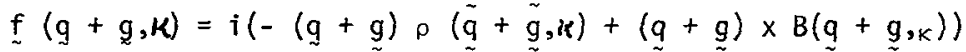

$$
\begin{aligned}
& \left.I_{\sim}^{\prime}(\underline{q}+\underset{\sim}{g}, k)=i(-\underset{\sim}{q}+\underset{\sim}{g}) u(\underset{\sim}{q}+\underset{\sim}{g}, k)+(\underset{\sim}{q}+\underset{\sim}{g}) \times \underset{\sim}{\omega}(\underset{\sim}{q}+\underset{\sim}{g}, k)\right)
\end{aligned}
$$

In real space, this decomposition gives (2) for $f$ and a similar result for I'. In insulators where $\underset{\sim}{z}{ }^{\text {eff }}(x)$ is non-zero $f$ is not analytic and the charge density cannot completely be described in terms of pseudoatoms $/ 2 /$.

One advantage of the formalism is that the pseudoatom is neutral

$$
\lim _{\sim} \rightarrow 0(q, k)=i \cdot \underset{\sim}{q}{\underset{z}{z}}^{e f f}(k) \cdot q \varepsilon^{-1}(\underset{\sim}{q}, q) v(\underset{\sim}{q}) / 4 \pi e^{2}=0
$$

Another is that it gives the potential which an electron sees when a phonon is present. The rigid part of this potential is

$$
\left.u(q+\underset{\sim}{q}, k)=(q+g) \cdot I^{\prime}(q+g, k) / \mid q+g\right)^{2}
$$

The main part of the effective interaction between the ions is $/ 3,2$ /

$$
V\left(q+g, k ; q+g^{\prime}, k^{\prime}\right)=W(q+g, k) \varepsilon^{-1}\left(q+\underline{q}, q+g^{\prime}\right) W\left(q+g^{\prime}, k^{\prime}\right) / v(q+g)
$$

Using (T7) and the inversion procedure $(7)$, the dynamical matrix becomes

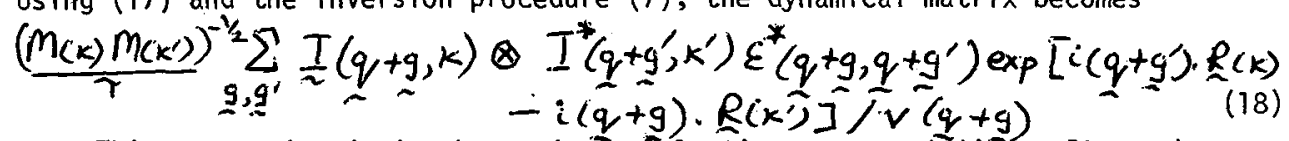

This expression is in the reciprocat-lattice representation. It can be 
generalised to other representations by considering $\varepsilon$ as a matrix and $\mathbb{I}$ as a 'vector'. Then the dynamical matrix in a general representation is

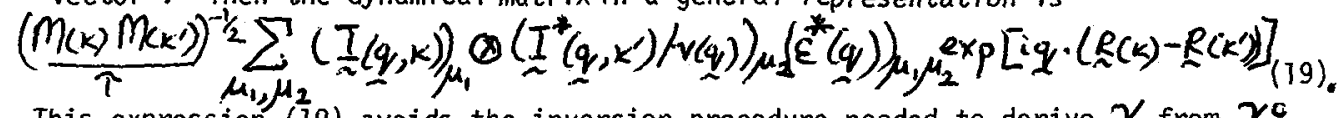
This expression (19) avoids the inversion procedure needed to derive $\chi$ from $\chi^{c}$. Using the R.P.A. expression for $\varepsilon$, the dynamical matrix becomes $\varrho^{\prime}+\mathbb{Q}^{\prime}$ where $c^{\prime}=\left(\frac{\left.\left.M_{(k)} M_{\left(k^{\prime}\right.}\right)\right)^{-y_{2}}}{\tau} \sum_{\mu}(I(q, k))_{\mu} \otimes\left(I^{*}\left(q, k^{\prime}\right) / v(q)\right)_{\mu}+\right.$ exchange, etc., terms

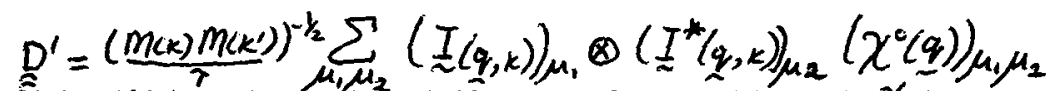
Sinha /4/ has obtained a simitar formular to this with $\chi$ in place of $\chi^{0}$;

however, his definition of $I$ is different from ours.

Equations (20 and (21) are useful when we can use the pseudoatom concept. Then we replace $I$ by $I_{\sim}^{\prime}$ and incorporate all the exchange, etc., effects into $\underset{\approx}{\mathcal{C}} \cdot I^{\prime}$ can then be written in the pseudoatom form (17), i.e.

$$
\left(I^{\prime}(q, k)\right)_{\mu}=\left(\nabla_{u}(q)\right)_{\mu}-(\nabla \times \underset{\sim}{w}(q))_{\mu}
$$

The neutraitity of the pseudoatom means that the cancellation between the large Coulombic attractive and repulsive terms has already been accomplished. If there is a suitable approximation for the potential $u$, and $\omega$ can be neglected, it is practical to calculate $\underset{\sim}{I}(q, k)$ in certain representations, e.g. $(\ell, m)$ orbitals or the tight-binding representation $/ 4 /$.

When $z(q, k)$ is pure imaginary in a cubic material, the only direction for $Z(q, k)$ is along $q$, so that $I^{\prime}(q, k)$ has no deformation part. When there is inversion symmetry, $\hat{\chi}(q, q+\tilde{q})$ is real, so that $\underset{\sim}{z}\left(\tilde{q}_{\tilde{\alpha}}\right)$ is pure imaginary provided $g . R(\kappa)$ is an integer times $\pi$. This occurs in cubic crystals with one ion per unit ceil or with the $\mathrm{NaCl}$ structure, but not with the diamond structure or the $\mathrm{A15}$ structure. Thus I' $(q, k)$ has no deformation in the alkali metals, nor in Nb, Mo, MOC and TaC, but may have significant deformation in Ge and Si and the A75 metals. It would be of interest to measure the change in electron-phonon coupling and in $T_{C}$ in $\mathrm{Nb}, \mathrm{Pb}$ and Mo caused by strains which alter the symmetry and thus allow deformation.

The second term of (12) is in the q-direction, so that if $q$ is perpendicular to $g$ it contributes $a$ deformation part to $I(q+g, k)$. If $I(q+\tilde{g}, k)$ is calculated from a band-structure calculation, this term is ñeglected, büt in metals it concontributes to the elastic constants.

\section{References}

/1/ Ball, M. A., J. Phys. C: Solid State Phys. 8 (1975) 3328.

Pickett, W. E., J. Phys. C: Solid State Phys. 12 (1979) 1491.

12/ Ba11, M. A. J. Phys. C: Solid State Phys. 10 (1977) 4921.

13/ Sham, L. J., Dynamical Properties of Solids I (1974) ed. by G. K. Horton and A. A. Máradudin (North-HoTl and, Amsterdam)

14/ Sinha, S. K., Dynamical Properties of Solids III (1980) ed. by G. K. Horton and A. A. Maradudin (North)-Hol Tand, Amsterdam) 